\title{
Chemotaxis Inhibition
}

National Cancer Institute

\section{Source}

National Cancer Institute. Chemotaxis Inhibition. NCI Thesaurus. Code C40752.

Chemotaxis Inhibition involves interference with, or restraint of, characteristic movement or orientation of an organism or cell along a chemical concentration gradient either toward or away from the chemical stimulus. 